\title{
Improving Varicella Investigation Completeness in Pennsylvania
}

\author{
Jonah Long, Wayne Fleming, Janine Strick \\ Pennsylvania Department of Health, Jackson Center, Pennsylvania, United States \\ Objective
}

The objective of this study was to evaluate the impact of efforts made to improve the completeness of select varicella (chickenpox) case investigation variables.

\section{Introduction}

Routine childhood administration of varicella-containing vaccine has resulted in the number of varicella (chickenpox) cases in Pennsylvania falling from nearly 3,000 cases in 2007 to less than 400 cases in 2017. Prior to 2018, the completeness of varicella case investigation data documented in Pennsylvania's electronic disease surveillance system (PA-NEDSS) was not routinely monitored by Department of Health (DOH) staff. A pilot project was initiated in April 2018 to monitor and improve completeness of select varicella case investigation variables.

\section{Methods}

Varicella cases reported to PA-NEDSS during MMWR year 2018 (MMWR weeks 1 - 26) in Pennsylvania (excluding Philadelphia County) with a classification status of probable or confirmed were included in the pilot project $(n=223)$. DOH epidemiology staff prioritized 11 key varicella investigation variables and developed a SAS program to identify cases with missing data, which were summarized in weekly reports and provided to DOH immunization staff for follow- up. DOH immunization staff reviewed missing data reports and communicated with case investigators to reconcile missing data. Varicella case data from the project period were compared with a 10-year baseline to evaluate the 11 targeted variables for change in percent completion.

\section{Results}

Percent completion of all 11 variables improved during the intervention period, with a median relative increase of $10.2 \%$ (range: $4.2 \%-25.5 \%$ ) compared to baseline. All but two variables (pregnancy status and number of days hospitalized) exhibited a statistically significant $(\mathrm{p}<0.05)$ improvement in percent completion. In addition, among eight variables that include an unknown response option, only one variable (number of varicella vaccine doses received) measured an increase in the percentage of unknown responses during the project period compared with baseline; however, this increase was not statistically significant $(\mathrm{p}=0.180)$.

\section{Conclusions}

Prioritization of key varicella investigation variables for improved completion was successful and did not result in significant increases of unknown responses. As varicella cases become less common, varicella case investigation data become increasingly important. Increased completeness of these data will enhance DOH communication of varicella surveillance findings, particularly for severe cases. Based on the success of this interagency collaboration, similar efforts are being developed for additional reportable conditions.

Table 1. Varicella variable completeness during 2008-2017 and 2018.

Variable

2008-2017

$(\mathrm{n}=8,895)$

2018
$(n=223)$

ISDS Annual Conference Proceedings 2019. This is an Open Access article distributed under the terms of the Creative Commons AttributionNoncommercial 4.0 Unported License (http://creativecommons.org/licenses/by-nc/3.0/), permitting all non-commercial use, distribution, and reproduction in any medium, provided the original work is properly cited. 
ISDS 2019 Conference Abstracts

ISDS

INTERNATIONAL SOCIETY

\begin{tabular}{|c|c|c|c|c|}
\cline { 2 - 5 } & $\begin{array}{c}\text { Mean Percent Complete } \\
\text { (standard deviation) }\end{array}$ & $\begin{array}{c}\text { Percent } \\
\text { Complete }\end{array}$ & $\begin{array}{c}\text { Relative Percent } \\
\text { Change }\end{array}$ & $\begin{array}{c}\chi^{2} \mathrm{p}- \\
\text { valu } \\
\mathrm{e}\end{array}$ \\
\hline Onset date & $92.4(2.9)$ & 99.6 & +7.8 & $<0.001$ \\
\hline Hospitalization & $90.8(5.0)$ & 100.0 & +10.2 & $<0.001$ \\
\hline Days hospitalized & $72.4(11.7)$ & 90.9 & +25.5 & $0.161^{4}$ \\
\hline Pregnant $^{2}$ & $89.8(3.2)$ & 97.7 & +8.8 & $0.0590^{4}$ \\
\hline Rash onset date & $94.2(1.3)$ & 99.6 & +5.7 & $<0.001$ \\
\hline Lesion severity & $89.9(1.7)$ & 99.6 & +10.7 & $<0.001$ \\
\hline Immunocompromised & $81.5(4.9)$ & 99.6 & +22.1 & $<0.001$ \\
\hline Complications & $81.2(7.4)$ & 99.6 & +22.6 & $<0.001$ \\
\hline $\begin{array}{c}\text { Transmission setting } \\
\text { known }\end{array}$ & $82.9(4.5)$ & 99.6 & +20.1 & $<0.001$ \\
\hline $\begin{array}{c}\text { Received varicella } \\
\text { vaccine }\end{array}$ & $90.9(1.8)$ & 99.6 & +9.5 & $<0.001$ \\
\hline $\begin{array}{c}\text { Varicella vaccine doses } \\
\text { received }\end{array}$ & $96.0(1.7)$ & 100.0 & +4.2 & $0.0204^{4}$ \\
\hline
\end{tabular}

${ }^{1}$ Denominator: Hospitalized cases; $\mathrm{n}=167$ (2008-2017), $\mathrm{n}=11$ (2018); ${ }^{2}$ Denominator: Female cases, $>12$ years; $\mathrm{n}=1,001$ (20082017), $n=44$ (2018); ${ }^{3}$ Denominator: Vaccinated cases; $n=5,037$ (2008-2017), $n=79$ (2018); ${ }^{4}$ Fisher exact (right-sided) 